\title{
Ulnar nerve palsy as a complication of closed both-bone forearm fracture in a pediatric patient: a case report
}

This article was published in the following Dove Press journal: International Medical Case Reports Journal

\section{Mohammad Q Hamdan \\ Bassem I Haddad \\ Ala Hawa \\ Sultan S Abdelhamid}

Faculty of Medicine, Special Surgery Department, Orthopedics and Trauma Department, The University of Jordan, Amman, II 942 Jordan
Correspondence: Mohammad Q Hamdan Faculty of Medicine, Special Surgery Department, Orthopedics and Trauma Department, The University of Jordan, Queen Rania Street, Amman, II 942 Jordan

Tel +962799746439

Fax +9 6265300820

Email mohamdan2000@gmail.com
Background: Fractures of both the ulna and radius, known as both-bone forearm fractures are common among the pediatric population. However, ulnar nerve palsy is a rare complication. Nerve damage can be due to multiple factors. Identification of the type of nerve damage is vital for proper management of this complication. Here, we present a case of ulnar nerve palsy complicating a closed both-bone forearm fracture in a pediatric patient. Furthermore, we explored how to best manage such cases and decrease permanent nerve damage through a literature review.

Case presentation: A 10-year-old boy presented to the emergency department (ED) 1 day after sustaining a closed right forearm fracture due to a fall. Examination at our ED revealed intact vascularity and nerve function. Reduction and casting were performed. On follow-up 7 days later, signs of ulnar nerve palsy in the form of decreased sensation in the little finger and weak abduction and adduction of the fingers were present. The patient was admitted and underwent closed reduction with percutaneous elastic stable intramedullary nailing. We found 14 case reports in the literature with similar case presentations. These fractures are commonly managed conservatively by closed reduction, casting, and rehabilitation. However, in both-bone forearm fractures, management began with observation, with surgical exploration being reserved for non-improving patients.

Conclusion: The uncommon occurrence of ulnar nerve palsy after closed forearm fractures in children should alert physicians to maintain a high index of suspicion and to thoroughly evaluate nerve function in children both before and after reduction of forearm fractures. Surgical exploration is recommended in cases of delayed recovery of nerve function.

Keywords: pediatric, fracture, peripheral nerve, palsy, both-bone forearm, case report

\section{Introduction}

Fractures of the radius and ulna, also called both-bone forearm fractures, are the third most common fractures in the pediatric population, accounting for $13-40 \%$ of all pediatric fractures. ${ }^{1,2}$ Despite the increased use of elastic stable intramedullary nailing (ESIN), many of these fractures are managed by closed reduction and casting because of the high remodeling potential in children. ${ }^{3}$ Surgical intervention using ESIN or plates is recommended if manual reduction fails to result in proper bone alignment. ${ }^{4}$

Ulnar nerve palsy is a rare complication of closed forearm fractures. It might be the result of the initial insult, nerve entrapment between bone fragments after reduction, or later entrapment by scar tissue. The type of nerve injury is 
Table I Summary of the reported cases of ulnar nerve palsy after closed forearm both-bone fracture

\begin{tabular}{|c|c|c|c|}
\hline Reference (year) & Patient & Management & Findings and outcome \\
\hline Ekiz et $\mathrm{al}^{7}(2017)$ & 13-year-old boy & $\begin{array}{l}\text { Closed reduction and elastic nailing. } \\
\text { Highlights the use of ultrasound. }\end{array}$ & Spontaneous recovery after 3 months. \\
\hline Shwartsmann et al ${ }^{8}(2016)$ & 17-year-old boy & $\begin{array}{l}\text { Ulnar sensory deficit present initially; open } \\
\text { repair and plate fixation. }\end{array}$ & $\begin{array}{l}\text { Ulnar nerve laceration. } \\
\text { Outcome not mentioned. }\end{array}$ \\
\hline Amit et $\mathrm{al}^{9}(2013)$ & Child, unspecified & Closed reduction. & $\begin{array}{l}\text { Spontaneous, almost full recovery after } \\
3 \text { months. }\end{array}$ \\
\hline Shimbashi et al ${ }^{10}(2013)$ & Article in Japanese & Article in Japanese. & Article in Japanese. \\
\hline Küçük et al" (2012) & 8-year-old boy & $\begin{array}{l}\text { Closed reduction. Surgical release of the } \\
\text { ulnar nerve after } 3 \text { months. }\end{array}$ & $\begin{array}{l}\text { Ulnar nerve entrapped in the callus. } \\
\text { Outcome unknown. }\end{array}$ \\
\hline Suganuma et $\mathrm{al}^{6}(2012)$ & 12-year-old girl & $\begin{array}{l}\text { Closed reduction and elastic nailing. } \\
\text { Neurolysis } 9 \text { weeks later. }\end{array}$ & No motor dysfunction after 6 months. \\
\hline Lu et al ${ }^{12}(2007)$ & 14-year-old boy & $\begin{array}{l}\text { Closed reduction with percutaneous pinning } \\
\text { of a distal radius fracture. }\end{array}$ & Spontaneous full recovery after 16 weeks. \\
\hline Hirasawa et al ${ }^{13}(2004)$ & 13-year-old girl & $\begin{array}{l}\text { Closed reduction and casting. Surgical } \\
\text { exploration and neurolysis after } 3 \text { months. }\end{array}$ & $\begin{array}{l}\text { Ulnar nerve entrapped at fracture site. Full } \\
\text { recovery in } 4 \text { months. }\end{array}$ \\
\hline Neiman et al ${ }^{14}(1998)$ & $\begin{array}{l}2 \text { patients, } \\
\text { unspecified }\end{array}$ & $\begin{array}{l}\text { Ulnar palsy before reduction. Treated by } \\
\text { closed reduction in both patients. }\end{array}$ & $\begin{array}{l}\text { Spontaneous recovery after } 20 \text { weeks in both } \\
\text { patients. }\end{array}$ \\
\hline \multirow[t]{2}{*}{ Stahl et al ${ }^{15}(1997)$} & $\begin{array}{l}\text { 10-year-old boy } \\
\text { 15-year-old boy }\end{array}$ & $\begin{array}{l}\text { Neurapraxia on presentation. Closed reduc- } \\
\text { tion and casting. Neurolysis under the oper- } \\
\text { ating microscope } 10 \text { weeks after reduction. } \\
\text { Closed reduction and casting. Neurapraxia } \\
\text { next day. Minimal internal neurolysis was } \\
\text { performed } 4 \text { months later. }\end{array}$ & $\begin{array}{l}\text { Nerve entrapped in hypertrophic scar. } \\
\text { Complete sensory recovery and partial motor } \\
\text { recovery after I year. } \\
\text { Nerve partially kinked by scar. } \\
\text { Full recovery within I month of surgery. }\end{array}$ \\
\hline & 9-year-old boy & $\begin{array}{l}\text { Palsy at presentation. Open reduction after } \\
\text { failure of closed reduction and nerve repair. }\end{array}$ & $\begin{array}{l}\text { Nerve entrapped in bony spike and partially } \\
\text { lacerated. } \\
\text { Full recovery after } 6 \text { months. }\end{array}$ \\
\hline Torpey et al ${ }^{16}(1996)$ & I5-year-old girl & $\begin{array}{l}\text { Ulnar palsy at presentation. Surgical explora- } \\
\text { tion of the ulnar nerve and fracture fixation } \\
\text { by plates and screws. }\end{array}$ & $\begin{array}{l}\text { Almost complete nerve laceration. Persistent } \\
\text { anesthesia, muscle atrophy, and weakness in } \\
\text { the ulnar nerve distribution after } 2 \text { years. }\end{array}$ \\
\hline
\end{tabular}

a significant factor in determining the type of management. There have been 14 such cases reported in the literature (Table 1). Here, we present a case of ulnar nerve palsy complicating a closed both-bone forearm fracture in a pediatric patient. This case report is written according to the recently published SCARE criteria as it is used for supporting transparency and accuracy in publication of case reports. ${ }^{5}$

\section{Case presentation}

A 10-year-old boy presented to the emergency department (ED) one day after sustaining a closed right forearm fracture due to a fall. He was admitted in another hospital the day prior, where he underwent closed reduction and received an above-elbow slab. He was referred to our hospital due to the inability of the former to achieve a good reduction. Examination at our ED revealed intact vascularity and nerve function. No signs of compartment syndrome were evident in the form of excessive pain or tense swelling. Radiography showed malreduction (Figure 1). Re-reduction and casting were successfully performed (Figure 2). Assessment of the ulnar nerve post-reduction was not possible as the boy was uncooperative due to pain. The patient was discharged and scheduled for a follow-up visit in the outpatient clinic 2 days later. The visit was rescheduled, and he was seen 7 days after discharge.

At the follow-up visit in the clinic, the patient still complained of sharp pain. Physical examination showed no swelling suggestive of compartment syndrome, pulses and capillary filling were normal, and median and radial nerves were intact; however, signs of ulnar nerve palsy in the form of decreased sensation in the little finger and weak abduction and adduction of the fingers were present. Radiography showed loss of reduction. Redisplacement could be explained by the fact that the patient was 10 years old, and as described by the study by Bowman 


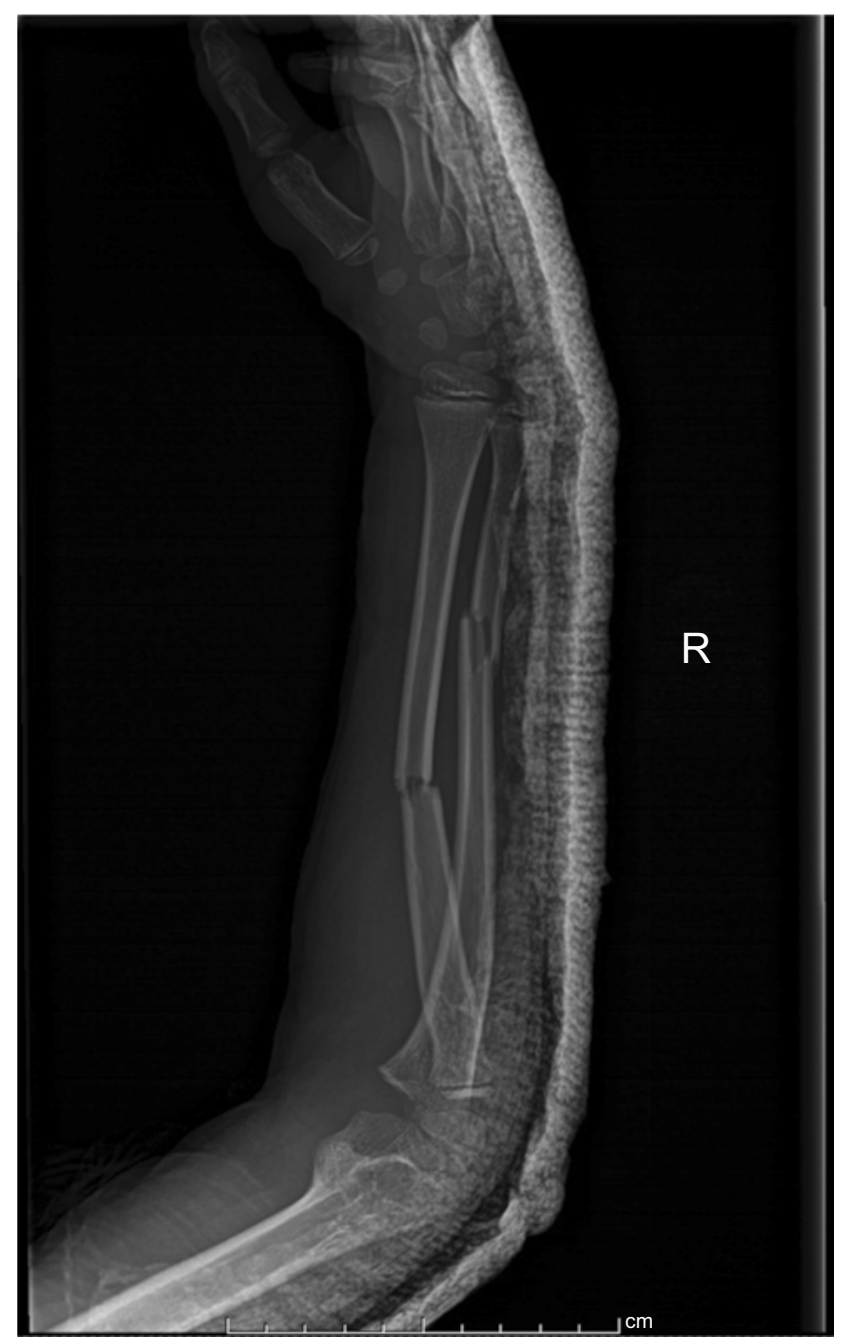

Figure I X-ray on presentation.

et al stating that reduction of both bone forearm fractures in children 10 years and older are more likely to fail. ${ }^{3}$ The patient was admitted and closed reduction with percutaneous ESIN under general anesthesia was performed. Two 2.5-mm elastic nails were used, retrogradely for the radius and anterogradely for the ulna. The postoperative radiograph is shown in Figure 3.

No improvement in the patient's sensory or motor deficit was seen after the surgery. As there were no available radiologists with experience in musculoskeletal ultrasonography in our hospital, and an electrodiagnostic study was not readily available, a non-contrast magnetic resonance (MR) image was obtained a day later, revealing a continuous right ulnar nerve without evidence of bony entrapment or surrounding edema. The patient was then discharged.

On follow-up 2 weeks post-operatively, the slab was removed, and radiography revealed excellent alignment. The patient was followed up on a regular basis (Figure 4A and B).

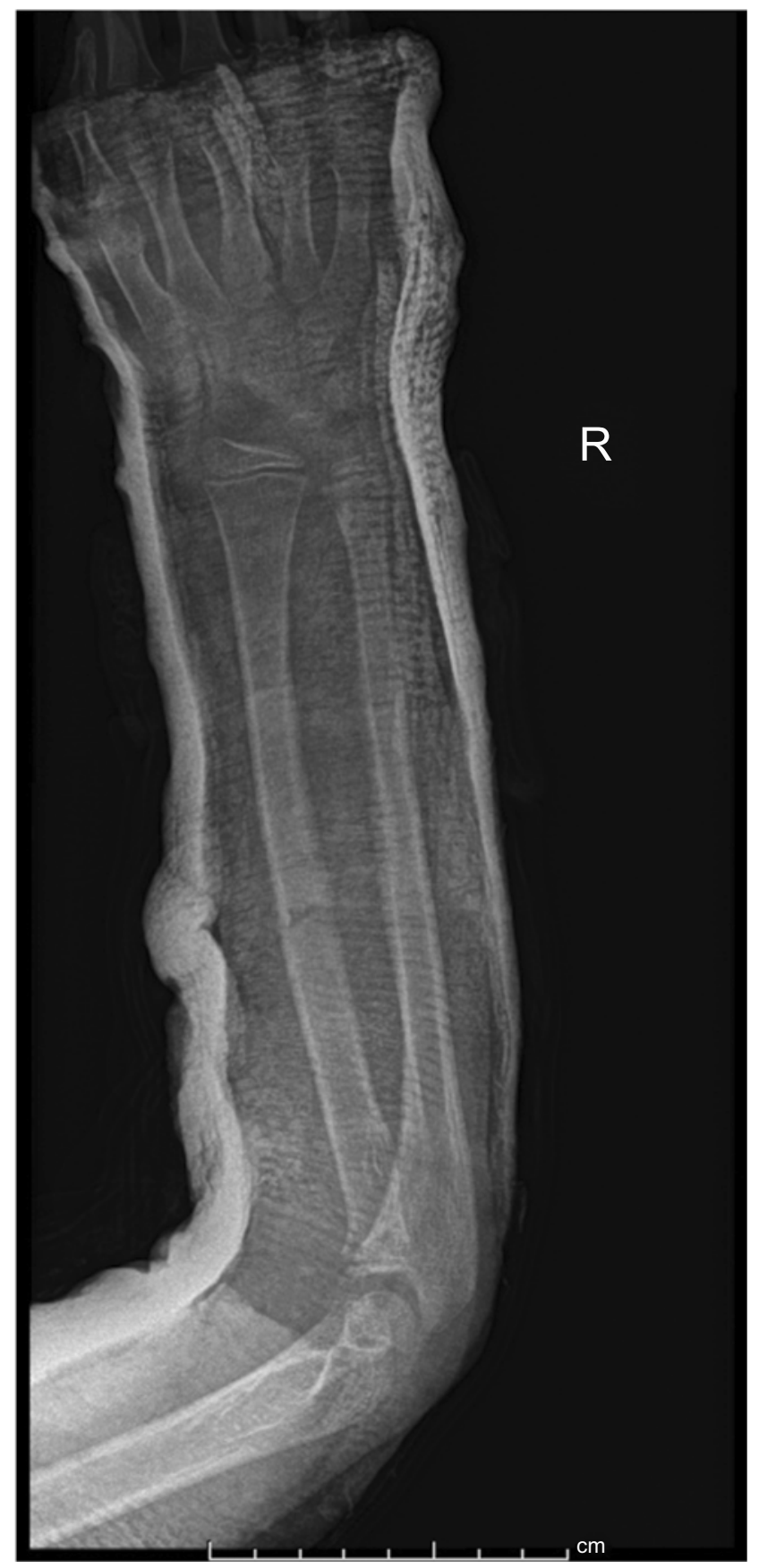

Figure 2 X-ray after closed reduction showing excellent alignment.

At the 5-month follow-up, the patient showed complete recovery of the ulnar nerve (normal sensation and range of motion, complete adduction and abduction of the fingers, and negative Froment's sign). The elastic nails were removed 1 month later (Figure 5).

Written informed consent was obtained from the patient for publication of this case report and accompanying images. No ethical approval is required for case reports as per university regulations. 

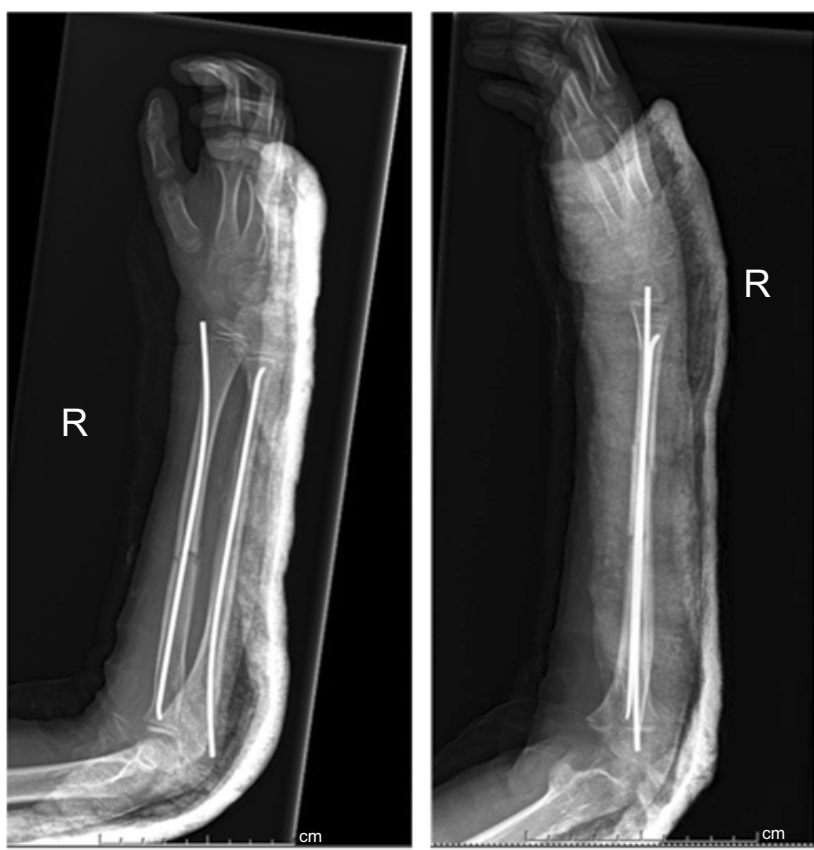

Figure 3 Initial postoperative X-ray.

\section{Discussion}

Both-bone forearm fractures in children are commonly managed conservatively by closed reduction and casting followed by rehabilitation. Surgical indications include open fractures, failed or unstable reductions, vascular injuries, and fractures in skeletally-mature individuals. ${ }^{4}$ Neurapraxia along the ulnar nerve distribution as a complication of closed forearm fracture is very rare. Suganuma et al listed more common nerve injuries from upper limb fractures including those involving the clavicle, humeral shaft, and supracondylar fractures, as well as shoulder dislocations. ${ }^{6}$ In the 14 reports of ulnar nerve injury following forearm fractures found in the literature, management began with observation, with surgical exploration being reserved for non-improving patients. Outcomes varied from case to case, as demonstrated in Table $1 .^{7-16}$

The ulnar nerve is protected by surrounding muscles in its passage under the deep layer of the flexor carpi ulnaris. Unless there is significant displacement and angulation of the ulna, the incidence of injury is rare. Ulnar nerve palsy might be the result of several causes. The nerve could be damaged by the initial injury as a result of nerve compression from surrounding edema or an injury could result from internal laceration or fibrosis. ${ }^{17}$ Entrapment of the nerve within fragments of the bone after closed reduction or within scars is another potential cause that can be surgically managed. ${ }^{8}$ In this reported case, ulnar nerve palsy occurred after a second manipulation of the

\section{A}
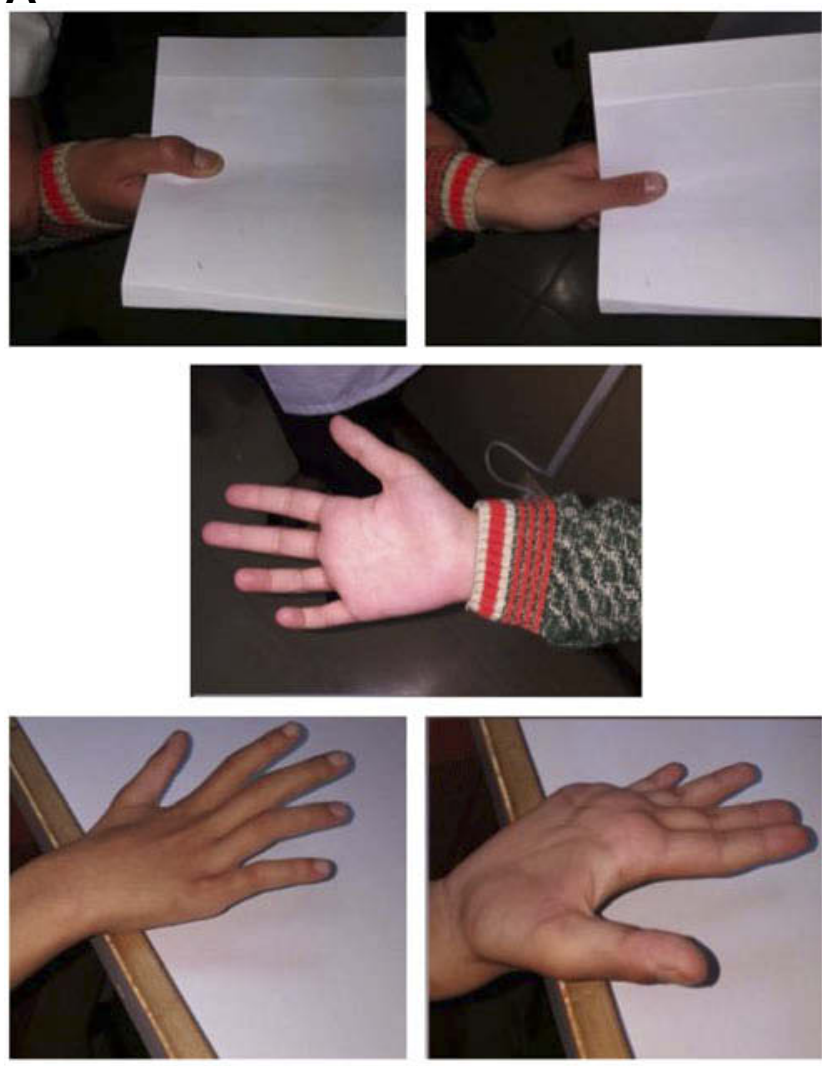

B

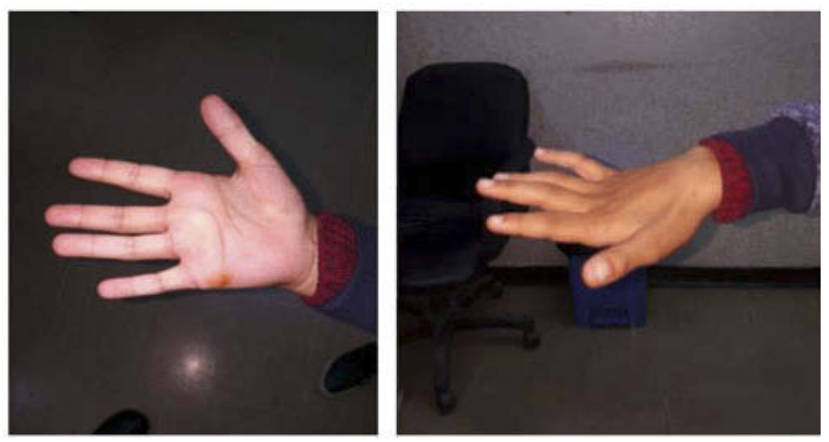

Figure 4 (A) Preoperative clinical images showing positive Froment's sign and clawing of the fingers; (B) Clinical images at the first postoperative follow-up showing improvement in finger abduction with mild clawing.

fracture. Neurapraxia was probably caused by traction and edema as there was no evidence of nerve entrapment or laceration. MR neurography (MRN) and MR imaging (MRI) have been shown to be sensitive for the diagnosis of suprascapular nerve injuries after shoulder trauma. ${ }^{18} \mathrm{MRN}$ is a novel imaging technique for direct imaging of spinal and peripheral nerves. It is a valuable adjunct to conventional MRI and is indicated in patients under consideration for surgery for peripheral nerve lesions or after trauma. ${ }^{19}$ However, to the best of our knowledge, no literature exists regarding the use of MRI and MRN for the evaluation of ulnar neuropathy after forearm 

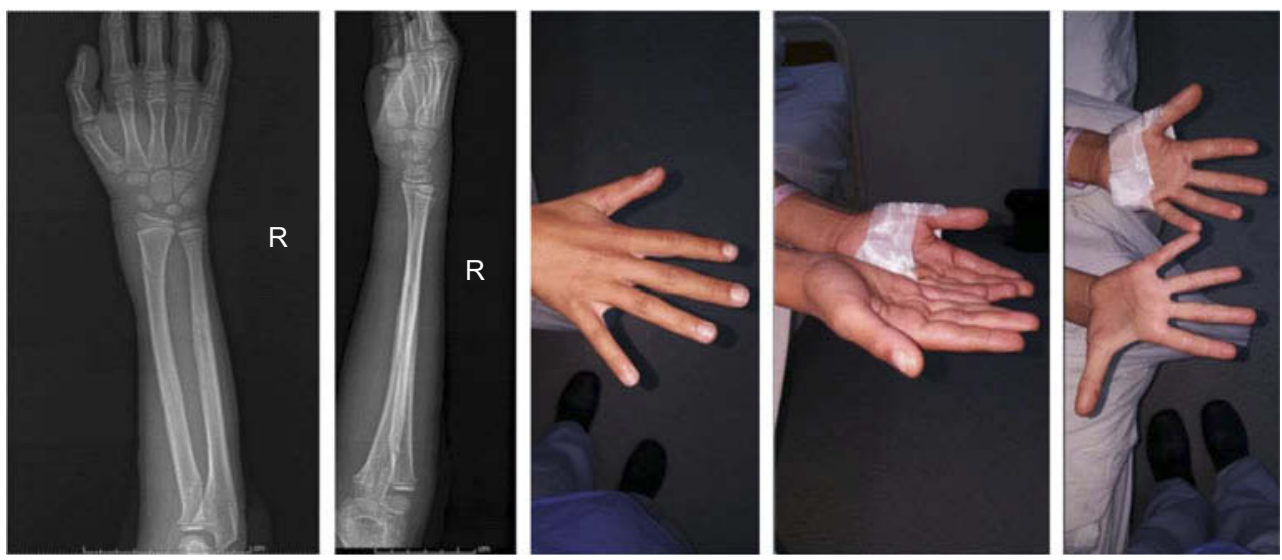

Figure 5 X-ray and clinical image after removal of C-nails showing complete healing and recovery.

fractures. Nevertheless, MRI was used to help diagnose the status of the ulnar nerve after forearm fractures in two reports. ${ }^{8,20}$ Ekiz et al recently recommended the use of ultrasonography for such fractures, highlighting its usefulness for detecting nerve injuries. ${ }^{7}$ Other authors have used nerve conduction studies. $^{12,20}$

As in this reported case, most other authors reported neurapraxia after reduction, resorting to surgery in such cases. The maneuvers used in reduction might be responsible for the ulnar nerve injury; in this patient, the reduction maneuver consisted of exaggeration of the deformity to disimpact the fracture fragments and disengage any interposing soft tissue, followed by traction and correction of the deformity. Few of the patients reported in the literature were uncooperative, restricting the ability of physicians to perform full physical examinations at the time of presentation. Amit et al reported the case of a child who developed features of neurapraxia on follow-up. ${ }^{9}$ The child was managed conservatively after MRI showed no nerve entrapment. The patient regained almost full motor and sensory functions after 3 months. This finding demonstrates the importance of precisely identifying the type of nerve injury, which consequently influences the choice of management. This can be achieved by different modalities including ultrasonography, electrodiagnostic studies, or magnetic resonance imaging, depending on the availability and experience at the treating hospital.

\section{Conclusion}

The uncommon occurrence of ulnar nerve palsy after closed forearm fractures in children should alert physicians to maintain a high index of suspicion and to thoroughly evaluate nerve function in children both before and after reduction of forearm fractures. MRI, ultrasound, or electrophysiological studies can aid assessment of the status of the nerve and the cause of the palsy. Surgical exploration is recommended in cases of delayed recovery of nerve function.

\section{Ethics approval and consent to participate}

No ethical/IRB approval is required for case reports as per University of Jordan regulations. Written informed consent was obtained from the patient as well as the patient's custodian (father) for publication of this case report and accompanying images.

\section{Data sharing statement}

Data generated or analyzed during this study are included in this article.

\section{Acknowledgments}

This research did not receive any specific grant from funding agencies in the public, commercial, or not-forprofit sectors.

\section{Author contributions}

Mohammad Q Hamdan: treating physician, conceptualization, visualization, writing original draft, review, and editing. Bassem I Haddad: writing original draft, review, and editing. Ala Hawa: data collection, literature review, and editing. Sultan S Abdelhamid: writing original draft, review, and editing. All authors gave final approval of the version to be published, and agree to be accountable for all aspects of the work. 


\section{Disclosure}

The authors report no conflicts of interest in this work.

\section{References}

1. Cheng JC, Ng BK, Ying SY, Lam PK. A 10-year study of the changes in the pattern and treatment of 6,493 fractures. J Pediatr Orthop. 1999;19:344-350. doi:10.1097/01241398-199905000-00011

2. Jones K, Weiner DS. The management of forearm fractures in children: a plea for conservatism. J Pediatr Orthop. 1999;19:811-815. doi:10.1097/01241398-199911000-00021

3. Bowman EN, Mehlman CT, Lindsell CJ, Tamai J. Nonoperative treatment of both-bone forearm shaft fractures in children: predictors of early radiographic failure. $J$ Pediatr Orthop. 2011;31:23-32. doi:10.1097/BPO.0b013e318203205b

4. Vopat ML, Kane PM, Christino MA, et al. Treatment of diaphyseal forearm fractures in children. Orthop Rev (Pavia). 2014;6:5325. doi:10.4081/or.2014.5325

5. Agha RA, Fowler AJ, Saetta A, et al. The SCARE statement: consensus-based surgical case report guidelines. Int $J$ Surg. 2016;34:180-186. doi:10.1016/j.ijsu.2016.08.014

6. Suganuma S, Tada K, Hayashi H, Segawa T, Tsuchiya H. Ulnar nerve palsy associated with closed midshaft forearm fractures. Orthopedics. 2012;35:e1680-1683. doi:10.3928/01477447-20121023-33

7. Ekiz T, Üçpunar H, Yıldız D. Ulnar neuropathy after forearm fracture in a child: the role of peripheral nerve ultrasound in the decision of management. Turk J Phys Med Rehab. 2018;64:87-88. doi:10.5606/ tftrd.2018.1577

8. Schwartsmann CR, Ruschel PH, Huyer RG. Ulnar nerve paralysis after forearm bone fracture. Rev Bras Ortop (English Edition). 2016;51:475-477. doi:10.1016/j.rboe.2015.09.017

9. Amit B, Ashish D, Vinit V, et al. Missed ulnar nerve injury and closed forearm fracture in a child. Chin J Traumatol. 2013; 16:246-248.
10. Shimbashi S, Kaoru T, Takeshi S, Shogo S, Hiroyuki T. Ulnar nerve palsy associated with forearm fracture in children: A case report. Cent Jpn J Orthop Surg Trauma. 2013;56:573-574.

11. Küçük L, Özdemir O, Coşkunol E. Ulnar nerve palsy after closed forearm fracture: a case report. Hand Microsurg. 2012;1:30-32. doi:10.2399/emd.12.09709

12. Lu CC, Chuo CY, Chen SK, Huang YH, Chou PH. Ulnar nerve palsy following fracture of the distal radius in an adolescent: a case report. Kaohsiung J Med Sci. 2007;23:151-155. doi:10.1016/S1607-551X (09)70391-2

13. Hirasawa H, Sakai A, Toba N, Kamiuttanai M, Nakamura T, Tanaka K. Bony entrapment of ulnar nerve after closed forearm fracture: a case report. J Orthop Surg (Hong Kong). 2004;12:122-125. doi:10.1177/ 230949900401200122

14. Neiman R, Maiocco B, Deeney VF. Ulnar nerve injury after closed forearm fractures in children. J Pediatr Orthop. 1998;18:683-685. doi:10.1097/01241398-199809000-00026

15. Stahl S, Rozen N, Michaelson M. Ulnar nerve injury following midshaft forearm fractures in children. $J$ Hand Surg Br. 1997;22:788-789.

16. Torpey BM, Pess GM, Kircher MT, Faierman E, Absatz MG. Ulnar nerve laceration in a closed both bone forearm fracture. $J$ Orthop Trauma. 1996;10:131-134. doi:10.1097/00005131-199602000-00011

17. Cho $\mathrm{CH}$, Kang $\mathrm{CH}$, Jung JH. Ulnar nerve palsy following closed fracture of the distal radius: a report of 2 cases. Clin Orthop Surg. 2010;2:55-58. doi:10.4055/cios.2010.2.1.55

18. Hassanien OA, Younes RL, Dawoud RM, Younis LM, Hamoda IM. Reliable MRI and MRN signs of nerve and muscle injury following trauma to the shoulder with EMG and clinical correlation. Egypt J Radiol Nuclear Med. 2016;47:929-936. doi:10.1016/j.ejrnm.2016.03.015

19. Du R, Auguste KI, Chin CT, Engstrom JW, Weinstein PR. Magnetic resonance neurography for the evaluation of peripheral nerve, brachial plexus, and nerve root disorders. J Neurosurg. 2010;112:362-371. doi:10.3171/2009.7.JNS09414

20. Batra A, Devgan A, Verma V, et al. Missed ulnar nerve injury and closed forearm fracture in a child. Chin J Traumatol. 2013;16:246-248.

\section{Publish your work in this journal}

The International Medical Case Reports Journal is an international, peer-reviewed open-access journal publishing original case reports from all medical specialties. Previously unpublished medical posters are also accepted relating to any area of clinical or preclinical science. Submissions should not normally exceed 2,000 words or 4 published pages including figures, diagrams and references. The manuscript management system is completely online and includes a very quick and fair peer-review system, which is all easy to use. Visit http://www.dovepress.com/testimonials.php to read real quotes from published authors. 